\title{
Jacopo Francesco Falà and Irene Zavattero (eds.), Divine Ideas in Franciscan Thought (XIIIth-XIVth Century). Flumen Sapientiae 8, Roma, Aracne, 2018, 504 pp., ISBN: 9788825521917. Cloth $€ 28$
}

\author{
Reseñado por RAFAEL RAMIS BARCELÓ \\ Universitat de les Illes Balears - IEHM, Palma, ES \\ r.ramis@uib.es
}

En la colección «Flumen Sapientiae», de la editorial Aracne, se presenta este libro colectivo, editado por Jacopo Francesco Falà e Irene Zavattero. Se trata de un conjunto de trabajos y de textos sobre las ideas divinas en el pensamiento franciscano. Por su extensión y por el número de autores, no podremos detenernos en cada trabajo, aunque sí daremos cuenta de los títulos de los capítulos, para pasar después a un juicio global.

Abre el libro Irene Zavattero (Universidad de Trento), «In Augustine's Footsteps. The Doctrine of Ideas in Franciscan Thought. Introductory Remarks» (pp. XI-XXVII), quien hace una presentación general de la obra. El primer trabajo es de Riccardo Saccenti (Universidad de Bergamo), «Sic bonum cognoscitur et similiter lux. Divine Ideas in the First Franciscan Masters (Alexander of Hales and John of La Rochelle)» (pp. 1-24). Seguidamente, Massimiliano Lenzi (La Sapienza), se ocupa de «La negazione delle idee e l"oscurantismo' dei filosofi. Bonaventura critico di Aristotele» (pp. 25-49), y Stève Bobillier (Université de Fribourg), trata en su capítulo de «Divine Ideas and Beatific Vision by Peter John Olivi» (pp. 51-73).

Luego, Timothy B. Noone (The Catholic University of America) y Carl A. Vater (St. John Vianney Theological Seminary) presentan un interesante trabajo «The Sources of Scotus's Theory of Divine Ideas» (pag. 75-99), enriquecido con sendos apéndices de Olivi y de Petrus de Trabibus, comentando el primer libro de las Sentencias. Siguiendo con Escoto, Jacopo F. Falà (Universidad de Macerata), se ocupa de «Divine ideas in the Collationes oxonienses» (pp. 101-133) y Ernesto Dezza (Pontificia Universidad Antonianum) trata acerca de «Giovanni Duns Scoto e gli instantia naturae» (pp. 135-159).

Seguidamente, Marina Fedeli (Universidad de Macerata), escribe sobre «Le idee divine e la relazione di imitabilità dell'essenza in Giacomo d'Ascoli» (pp. 161-176); Davide Riserbato (Universidad Católica del Sacro Cuore) dedica su capítulo a «Ut induit rationem ideae. L'essenza divina e l'essere intelligibile: identità (e differenza) secondo Guglielmo di Alnwick» (pp. 177-201) y Chiara Paladini (Universidad de L'Aquila) aborda el tema «Exemplar Causality as similitudo aequivoca in Peter Auriol» (pp. 203-238).

El capítulo central y el más extenso, con diferencia, es el de William Duba (Universidad de Fribourg), Roberta Padlina (Universidad de Fribourg) y Christopher Schabel (Universidad de Chipre), «From Scotus to the Platonici: Hugh of Novocastro, Landulph 
Caracciolo and Francis of Meyronnes» (pp. 239-369), que incluye un rico apéndice documental, en el cual se estudia el tratamiento que estos tres autores hicieron en sus comentarios de unos pasajes del primer libro de las Sentencias.

A continuación, Garrett Smith (Rheinische Friedrich-Wilhelms-Universität Bonn) escribe sobre «Petrus Thomae on Divine Ideas and Intelligible Being» (pp. 371-399); Alessandro Ghisalberti (Universidad Católica del Sacro Cuore) lleva a cabo una bella síntesis en «Le idee divine in Guglielmo di Ockham (pag. 401-426)» y Andrea Nannini (Universidad de Varsovia) dedica su contribución al tema «Immensa exemplaritas. La dottrina delle idee nella metafisica di Giovanni da Ripa. I Sent., d. 35» (pp. 427-459).

Por último, Alessandro Domenico Conti (Universidad de L'Aquila), en su ajustado y preciso capítulo final, titulado «Late Medieval Exemplarism. A Philosophical Assessment» (pag. 461-487), hace un estado de la cuestión, que conecta claramente con los propósitos que indicaba Zavattero en el prólogo.

Los comentarios al primer libro de las Sentencias son el itinerario a través del cual estos filósofos y teólogos franciscanos van mostrando su comprensión del problema de las ideas divinas, en un continuum que este libro traza con especial detalle. Lejos del esquema de tantos manuales (San Buenaventura - Escoto - Ockham), el libro da relieve a muchos autores a menudo preteridos y se enlaza con la historiografía más reciente, que ha mostrado particularmente la originalidad y la influencia de autores como Olivi o Pierre Auriol.

El problema que se dirime a lo largo del libro es la recepción del bagaje de la filosofía aristotélica por parte de los franciscanos en el tema concreto de las ideas divinas. La primera generación de hijos de San Francisco, al compás del pensamiento de su tiempo, estuvo fuertemente ligada al ejemplarismo agustiniano, de modo que se mantuvo alejada del aristotelismo metafísico que en aquellos momentos se estaba empezando a conocer en Occidente. Para San Agustín, como es sabido, Dios creó el mundo gracias a las ideas ejemplares que existen en Él. De este modo, el mundo es un reflejo de las ideas divinas. De este modo, las cosas existen en tanto que son la realización de esas ideas divinas y, así, la verdad de esas cosas depende de la conformidad con las mismas.

Estos primeros filósofos franciscanos son Alejandro de Hales, Juan de la Rochelle, San Buenaventura o Pierre de Jean Olivi. Podríamos añadir que Olivi es ya un autor de transición, aunque -en cuanto a las ideas divinas- aún muy ligado a la tradición agustiniana, pues no negaba la existencia de las ideas divinas, aunque para él no había una verdadera pluralidad de ideas en Dios. A medida que se avanzamos en el siglo XIII, asistimos a un agustinismo cada vez más distorsionado, que discutía expresa o tácitamente con los límites del pensamiento de Santo Tomás.

Otros autores, como Escoto y Ockham, negaron estos puntos, dando preeminencia a la Sagrada Escritura sobre la filosofía. Con ello, las ideas ejemplares, en su multiplicidad, dependían -para Escoto- de la voluntad de Dios. En su trabajo, Falà muestra la gran influencia de Enrique de Gante sobre las Collationes oxonienses. Para Escoto, las cosas dependían 
de la voluntad divina no solo en lo tocante a su existencia, sino también en lo referente a su esencia. Ghisalberti muestra cómo Ockham radicalizó aún más la postura escotista, enfatizando, ante todo, la libertad divina: la creatura, en sí misma, era la idea. Con ello, se desmantelaba por completo el ejemplarismo.

En realidad, podría decirse que Escoto -mucho más que Ockham- es el eje del libro, puesto que recogió la herencia agustiniana y la rebatió, mientras que muchos otros elaboraron sus doctrinas a la vera del Doctor Subtilis, aunque a menudo, con críticas hacia su pensamiento. Ello da lugar a un tercer grupo de autores (Giacomo da Ascoli, Pere Tomàs o Pierre Auriol), que elaboraron un sistema propio en el cual encajaron de forma distinta la cuestión de las ideas divinas.

Algunos autores como Giovanni da Ripa quisieron dar una segunda oportunidad a las ideas divinas, tal y como explica Andrea Nannini. Da Ripa quiso desandar el camino de Escoto y Ockham y apuntalar una metafísica de corte neoplatónico, realmente compleja. Asimismo, otros autores como François de Meyronnes o Pere Tomàs, intentaron repensar a Escoto y concordarlo hasta donde pudieron con la tradición agustiniana.

Este libro muestra la riqueza de la tradición franciscana y marca una pauta hermenéutica muy válida, pues pasa un fino plumero por las doctrinas de algunos autores de gran valor, a veces ladeados, con el fin de mostrar un mapa genealógico de la comprensión de las ideas divinas. Los sucesivos capítulos muestran la situación "preescotista» y «postescotista», subrayando siempre el peso del maestro escocés como crítico de sus antecesores y de Santo Tomás, así como también las muy «sutiles» críticas al Doctor Sutil, por parte de sus discípulos y seguidores.

Por ello, hay que concluir mostrando la gran libertad de posturas que encontramos entre los autores franciscanos: prácticamente todos los aquí estudiados mantuvieron una posición distinta de los demás. El libro tiene un orden cronológico, que facilita entenderlas ordenadamente, e incluso los apéndices ayudan a comprender ciertos problemas, mediante el análisis del acervo común de los Comentarios a Pedro Lombardo. Este mismo volumen podría tener una segunda parte con la recepción de estas doctrinas en las escuelas -las vías escolásticas- del Renacimiento y Barroco (especialmente, el escotismo y el nominalismo), que demostraría que estas mismas ideas continuaron siendo objeto de debate hasta el Barroco tardío.

Cabe felicitar a los autores por un libro tan acertado, que -con la misma metodologíapodrían extender a otros temas candentes de la tradición franciscana medieval (los universales, la psicología, ética, política...). Los lectores agradecerían su esfuerzo y su rigor, del mismo modo que alaban ahora la valiosa labor de Jacopo Francesco Falà y de Irene Zavattero, para editar este volumen, que resulta del máximo interés para todos los expertos en filosofía medieval. 